\title{
Papers
}

\section{Anthropometry and body composition of 18 year old men according to duration of breast feeding: birth cohort study from Brazil}

\author{
Cesar G Victora, Fernando C Barros, Rosângela C Lima, Bernardo L Horta, Jonathan Wells
}

\begin{abstract}
Objective To assess the association between duration of breast feeding and measures of adiposity in adolescence.

Design Population based birth cohort study. Setting Pelotas, a city of 320000 inhabitants in a relatively developed area in southern Brazil. Participants All newborn infants in the city's hospitals were enrolled in 1982; 78.8\% (2250) of all male participants were located at age 18 years when enrolling in the national army.

Main outcome measures Weight, height, sitting height, subscapular and triceps skinfolds, and body composition (body fat, lean mass).

Results Neither the duration of total breast feeding nor that of predominant breast feeding (breast milk plus non-nutritive fluids) showed consistent associations with anthropometric or body composition indices. After adjustment for confounding factors, the only significant associations were a greater than $50 \%$ reduction in obesity among participants breast fed for three to five months compared with all other breastfeeding categories $(\mathrm{P}=0.007)$ and a linear decreasing trend in obesity with increasing duration of predominant breast feeding $(P=0.03)$. Similar significant effects were not observed for other measures of adiposity. Borderline direct associations also occurred between total duration of breast feeding and adult height $(\mathrm{P}=0.06)$. Conclusions The significant reduction in obesity among children breast fed for three to five months is difficult to interpret, as no a priori hypothesis existed regarding a protective effect of intermediate duration of breast feeding. The findings indicate that, in this population, breast feeding has no marked protective effect against adolescent adiposity.
\end{abstract}

\section{Introduction}

Whether breast feeding protects against obesity is a hotly debated issue in the literature. In a review in 2001, Butte concluded that "the protective effect of breastfeeding on later obesity remains controversial." Later in 2001 Dietz reviewed two recent papers from the United States. ${ }^{2}$ The first reported a significant association between any breast feeding and being at risk of overweight (85th to 94th centiles of body mass index), but not with actual overweight (95th centile or above), for children aged 3-5 years. ${ }^{3}$ The second paper showed that children aged 9-14 years who had been mostly breast fed for the first six months of life had a $20 \%$ lower risk of overweight than those who were only or mostly fed infant formula. ${ }^{4}$ In 2003 Dewey suggested that most large studies show a protective effect of breast feeding against overweight in children and adolescents. ${ }^{5}$

We report on a birth cohort of over 2000 male Brazilians followed for 18 years, for whom detailed breastfeeding information was collected in early childhood. In addition to several anthropometric measures of adiposity, we ascertained body composition through bio-impedance.

\section{Methods}

Pelotas (population 320000 ) is a relatively affluent city in southern Brazil. The population is mostly of European background. The mean annual gross domestic product per capita is about US\$2700 (£1690; €2398), and infant mortality in 1982 was 38 per thousand.

The study recruited all 5914 infants born alive during 1982 in the three maternity hospitals in Pelotas (over 99\% of all city births). ${ }^{6}{ }^{7}$ The infants were examined, and their mothers were interviewed. In early 1983 children born in January-April 1982 were sought at home. In 1984 and 1986 all households in the city were visited in search of cohort children; $87 \%$ and $84 \%$ of the original cohort were located. Duration of breast feeding and age at introduction of fluids and foods were recorded. In 2000 we invited men in the cohort who were registering at the local army base to join the study. Informed consent was obtained in all phases of the study, and confidentiality was ensured. A single anthropometrist carried out each measurement on all participants.

We used standard definitions of breast feeding. ${ }^{8}$ Total duration in months and days was collected at the 1983, 1984, and 1986 follow ups. Exclusive breast feeding was of short duration, because virtually all children also received herbal teas or water from the first week of life and were thus classified as predominantly breast fed. Duration of predominant breast feeding recorded the age when foods other than breast milk or teas or
Post-Graduate Programme in Epidemiology, Universidade Federal de Pelotas, CP 464, 96001-970, Pelotas, RS, Brazil Cesar G Victora professor

Rosângela C Lima post-doctoral fellow

PAHO/WHO

Latin-American

Center for

Perinatology and

Human

Development,

Montevideo,

Uruguay

Fernando Barros

consultant

Faculty of Medicine, Catholic University of Pelotas, Brazil

Bernardo L Horta associate professor

Institute of Child Health, University of London, London Jonathan Wells lecturer

Correspondence to: C G Victora cvictora@ terra.com.br

bmj.com 2003;327:901 
water were introduced. We used the earliest available information in order to minimise recall bias.

Confounding variables were measured in 1982: monthly family income, maternal education, prepregnancy body mass index (in $\mathrm{kg} / \mathrm{m}^{2}$; height was measured soon after delivery, and weight was obtained from antenatal records or by recall), smoking during pregnancy (non-smokers, $0-14$, or $\geq 15$ cigarettes a day), birth weight, and gestational age (estimated by the date of the last menstrual period and recorded as less than $37,37-38,39-41$, or $\geq 42$ weeks or unknown). We also collected information on confounders in 2000: skin colour (self reported, classified as white or other), physical activity (minutes per week spent on physical exercise), type of diet (Block classification" ${ }^{9}$ best low fat food, low fat food, eating American diet, diet is quite high in fat, diet is high in fat), daily smoking, and alcohol intake in the preceding week.

We measured several outcomes in 2000. We measured standing and sitting height with a CMS stadiometer (London, UK) and obtained leg length by subtraction. We weighed participants in their underpants with a Tanita body fat analyser scale (model TBF-305, Tokyo, Japan). We measured subscapular and triceps skinfolds by using a Holtain skinfold caliper (Dyfed, UK). We used standard World Health Organization definitions and reference curves. ${ }^{10}$ We defined overweight as body mass index at or above the 85 th centile of the sex and age specific value and obesity as body mass index at or above the 85 th centile plus subscapular and triceps skinfolds at or above the 90th centile. We repeated all analyses with body mass index cut-offs of $25 \mathrm{~kg} / \mathrm{m}^{2}$ and $30 \mathrm{~kg} / \mathrm{m}^{2}$.

We estimated fat mass and fat-free mass in $\mathrm{kg}$ by using the Tanita bio-impedance scale. A validation substudy in a mirror sample of 48 participants in the age range of the study cohort assessed total body water by deuterium dilution. ${ }^{11}$ We used the resulting validation equation (total body water $=4.437+(0.378 \times$ weight $)+$ $\left(0.189 \times\right.$ height $\left.^{2}\right) /$ impedance standard $)$ to calculate fat mass (total body water/0.732) and fat-free mass (weight minus fat mass). We calculated percentage fat mass by dividing fat mass by total weight. We also calculated fat mass/height ${ }^{2}$ and fat-free mass/ height $^{2}$. We selected the power of two because log-log regressions of fat and fatfree mass in $\mathrm{kg}$ over height showed regression coefficients of 2.12 and $2.05 .^{12}$

We analysed dichotomous outcomes by using $\chi^{2}$ tests for heterogeneity and for linear trends in proportions. We used logistic regression to adjust for confounding. We compared means by using analysis of variance (crude analyses) and general linear models (adjusted analyses). Except for birth weight (a continuous variable), we categorised confounders as shown in table 1 .

\section{Results}

Of the 3037 liveborn boys in the cohort, we examined $2250(74.1 \%)$ in 2000 , and $143(4.7 \%)$ are known to have died. We therefore traced $78.8 \%$ of the original cohort. Another 37 cohort members were identified but refused to participate.

Table 1 shows that middle class participants were more often traced than either poor or wealthy ones. Regarding maternal education, follow up rates were
Table 1 Percentage of cohort located according to socioeconomic characteristics, birth weight, and breast feeding

\begin{tabular}{|c|c|c|}
\hline Baseline characteristic & $\begin{array}{l}\text { Original cohort } \\
\text { (No (\%)) }\end{array}$ & $\begin{array}{l}\text { No }(\%) \text { traced } \\
\text { in } 2000\end{array}$ \\
\hline \multicolumn{3}{|c|}{ Monthly family income (US\$) in 1982: } \\
\hline$\leq 50$ & $666(22.0)$ & $483(72.5)$ \\
\hline $51-150$ & $1463(48.4)$ & $1170(80.0)$ \\
\hline $151-300$ & $544(18.0)$ & $456(83.8)$ \\
\hline $301-500$ & $184(6.1)$ & $146(79.3)$ \\
\hline$>500$ & $167(5.5)$ & $128(76.6)$ \\
\hline Total & $3024^{*}$ & $\mathrm{P}<0.001 \dagger$ \\
\hline \multicolumn{3}{|c|}{ Maternal schooling (years) in 1982: } \\
\hline $0-4$ & $1008(33.2)$ & $768(76.2)$ \\
\hline $5-8$ & $1288(42.5)$ & $1048(81.4)$ \\
\hline $9-11$ & $330(10.9)$ & $249(75.5)$ \\
\hline$\geq 12$ & $406(13.4)$ & $323(79.6)$ \\
\hline Total & $3032^{*}$ & $\mathrm{P}=0.008 \dagger$ \\
\hline \multicolumn{3}{|l|}{ Birth weight $(\mathrm{g})$ in 1982: } \\
\hline$<2500 \mathrm{~g}$ & $244(8.0)$ & $189(77.5)$ \\
\hline$\geq 2500 \mathrm{~g}$ & $2791(92.0)$ & $2344(78.9)$ \\
\hline Total & $3035^{\star}$ & $\mathrm{P}=0.30 \dagger$ \\
\hline \multicolumn{3}{|c|}{ Duration of total breast feeding (months), 1983-6: } \\
\hline$<1$ & $636(23.3)$ & $511(80.3)$ \\
\hline $1-2.9$ & $708(25.9)$ & $577(81.5)$ \\
\hline $3-5.9$ & $611(22.3)$ & $519(84.9)$ \\
\hline $6-8.9$ & $261(9.5)$ & $210(80.5)$ \\
\hline $9-11.9$ & $114(4.2)$ & $90(78.9)$ \\
\hline$\geq 12$ & 405 (14.8) & $328(81.0)$ \\
\hline Total & $2735^{\star}$ & $\mathrm{P}=0.29 \dagger$ \\
\hline \multicolumn{3}{|c|}{ Duration of predominant breast feeding (months), 1983-6: } \\
\hline$<1$ & $757(28.9)$ & $619(81.8)$ \\
\hline $1-1.9$ & $405(15.4)$ & $328(81.0)$ \\
\hline $2-2.9$ & $489(18.6)$ & 407 (83.2) \\
\hline $3-3.9$ & $662(25.2)$ & $561(84.7)$ \\
\hline$\geq 4$ & $309(11.8)$ & $243(78.6)$ \\
\hline Total & $2622^{\star}$ & $\mathrm{P}=0.17 \dagger$ \\
\hline
\end{tabular}

*Total numbers do not add to 3037 owing to missing information.

$+\chi^{2}$ test for heterogeneity ( $\chi^{2}$ test for proportions; analysis of variance for means).

highest for the 5-8 years and $\geq 12$ years groups. No significant differences in follow up occurred according to birth weight or duration of breast feeding. Only $8.4 \%$ of all mothers reported not having attempted to breast feed, and 14.9\% reported breast feeding for 1-29 days. Misclassification between these two groups seemed to be frequent, ${ }^{13}$ and we merged them in the analyses.

Both short (less than one month) and long (12 months or more) durations of breast feeding were more prevalent in poor families with less educated mothers (data available on request). Non-white infants tended to be breast fed for longer than white ones, and birth weight was inversely associated with duration of breast feeding. Similar patterns occurred for predominant breast feeding. Income, maternal education, smoking, skin colour, maternal body mass index, gestational age, and birth weight were treated as

Table 2 Distribution of sample according to key indicators $(\mathrm{n}=2250)$

\begin{tabular}{lcc} 
Sample characteristic & No & $\%$ \\
\hline Overweight & 392 & 17.4 \\
\hline Obese & 182 & 8.1 \\
\hline Daily smokers & 356 & 15.8 \\
\hline Physical activity $<90$ min/week & 403 & 17.9 \\
\hline High fat diet & 1085 & 48.2 \\
\hline Alcohol intake in previous week & 1352 & 60.1
\end{tabular}


Table 3 Anthropometry and body composition of 18 year old men according to total duration of breast feeding. Values are means (SDs) unless stated otherwise

\begin{tabular}{|c|c|c|c|c|c|c|c|c|}
\hline \multirow[b]{2}{*}{ Outcomes } & \multicolumn{6}{|c|}{ Duration of total breast feeding (months) } & \multirow[b]{2}{*}{ P value* } & \multirow[b]{2}{*}{ All participants } \\
\hline & $<1$ & $1-2$ & $3-5$ & $6-8$ & $9-11$ & $\geq 12$ & & \\
\hline Overweight (No (\%)) & $69(14.1)$ & 75 (13.5) & $55(11.0)$ & $33(16.2)$ & $17(19.3)$ & $44(13.7)$ & 0.3 & $291(13.5)$ \\
\hline Obese (No (\%)) & $47(9.6)$ & $50(9.0)$ & $19(3.8)$ & $22(10.8)$ & $9(10.2)$ & $27(8.4)$ & 0.004 & $125(8.1)$ \\
\hline Body mass index & $22.5(3.8)$ & $22.3(3.6)$ & $22.1(3.2)$ & $22.6(4.4)$ & $22.9(3.7)$ & $22.5(4.2)$ & 0.25 & $22.4(3.8)$ \\
\hline Fat mass percentage & $17.6(2.9)$ & $17.8(2.8)$ & $17.7(2.8)$ & $17.9(3.0)$ & $18.3(2.6)$ & $17.9(2.7)$ & 0.42 & $17.8(2.8)$ \\
\hline Fat mass/height ${ }^{2}$ & $4.0(1.2)$ & $4.0(1.1)$ & $3.9(1.0)$ & $4.1(1.3)$ & $4.2(1.0)$ & $4.1(1.3)$ & 0.19 & $4.0(1.1)$ \\
\hline Lean mass/height ${ }^{2}$ & $18.5(2.9)$ & $18.3(2.7)$ & $18.2(2.5)$ & $18.6(3.2)$ & $18.7(2.9)$ & $18.4(3.1)$ & 0.27 & $18.3(2.8)$ \\
\hline Height in $\mathrm{cm}$ & $172.7(6.9)$ & $173.1(6.8)$ & $173.5(6.5)$ & $174.3(7.0)$ & $174.7(6.8)$ & $173.9(6.7)$ & $0.001 \dagger$ & $173.4(6.8)$ \\
\hline $\begin{array}{l}\text { Percentage leg/total } \\
\text { height }\end{array}$ & $44.5(1.4)$ & $44.6(1.3)$ & $44.7(1.3)$ & $44.8(1.3)$ & $44.7(1.2)$ & $44.7(1.5)$ & $0.02 \dagger$ & $44.6(1.3)$ \\
\hline No of participantsł & 489 & 555 & 498 & 204 & 88 & 321 & & 2155 \\
\hline
\end{tabular}

${ }^{\star}$ Test for heterogeneity $\left(\chi^{2}\right.$ test for proportions; analysis of variance for means).

tTest for linear trend.

¥The number of participants ranged from 2127 to 2155 , depending on the outcome.

potential confounders in the multivariable analyses. No associations occurred between breast feeding and current behavioural variables (smoking, alcohol drinking, type of diet, or physical exercise), but we retained these variables in the model as covariates. Table 2 shows characteristics of the sample in 2000.

Table 3 shows the unadjusted effects of total duration of breast feeding. No significant associations occurred with the prevalence of overweight or with mean body mass index, fat, or fat-free mass, but obesity was about three times less prevalent in participants who were breast fed for three to five months than in the other categories $(\mathrm{P}=0.004)$. Height increased steadily with duration of breast feeding until 11 months, with a significant overall linear trend. A significant linear association also occurred with percentage leg length, but the differences were small.

Table 4 shows adjusted analyses of overweight and obesity. Total duration of breast feeding remained unassociated with overweight, but the lower risk of obesity for participants breast fed for three to five months persisted, with an adjusted odds ratio of 0.41 compared with those breast fed for 12 months or longer $(\mathrm{P}=0.006)$. Table 5 shows adjusted analyses of continuous outcomes. No association occurred between total duration of breast feeding and mean body mass index, fat, or fat-free mass. The association with height was almost significant $(\mathrm{P}=0.06)$, but differences were small. No association with leg length occurred.

We repeated all analyses for predominant breast feeding (table 6). In the crude analyses, we found an inverse association with obesity $(\mathrm{P}=0.03)$ and direct associations with height $(\mathrm{P}=0.03)$ and possibly with percentage leg length $(\mathrm{P}=0.06)$. Adjustment for confounding confirmed the lack of association with overweight (table 7). However, we found evidence of a protective effect against obesity $(\mathrm{P}=0.03)$, although children who were predominantly breast fed for at least four months showed a slight increase compared with those breast fed for three months.

Table 8 shows that after adjustment for confounders no significant associations occurred between duration of predominant breast feeding and body mass index, fat, fat-free mass, height, or percentage leg length. We repeated all analyses with the adult cut-offs

Table 4 Logistic regression analyses for prevalence of overweight and obesity among 18 year old men according to duration of total breast feeding $(\mathrm{n}=2082)$

\begin{tabular}{|c|c|c|c|c|c|c|c|c|}
\hline \multirow[b]{2}{*}{ Outcomes } & \multirow[b]{2}{*}{ Model } & \multicolumn{6}{|c|}{ Odds ratio $(95 \% \mathrm{Cl})$ according to duration of total breast feeding (months) } & \multirow[b]{2}{*}{$P$ value ${ }^{*}$} \\
\hline & & $<1$ & $1-2$ & $3-5$ & $6-8$ & $9-11$ & $\geq 12$ & \\
\hline \multirow[t]{2}{*}{ Overweight (\%) } & Crude & $1.04(0.69$ to 1.56$)$ & $0.98(0.66$ to 1.47$)$ & $0.78(0.51$ to 1.19$)$ & 1.21 (0.74 to 1.98$)$ & 1.51 (0.81 to 2.78$)$ & 1.0 & 0.27 \\
\hline & Adjusted $†$ & $1.14(0.77$ to 1.68$)$ & $0.91(0.61$ to 1.35$)$ & $0.85(0.57$ to 1.27$)$ & $0.86(0.53$ to 1.40$)$ & $1.34(0.74$ to 2.44$)$ & 1.0 & 0.41 \\
\hline \multirow[t]{2}{*}{ Obese (\%) } & Crude & $1.16(0.71$ to 1.91$)$ & $1.08(0.66$ to 1.76$)$ & $0.43(0.24$ to 0.79$)$ & 1.32 (0.73 to 2.38$)$ & $1.24(0.56$ to 2.74$)$ & 1.0 & 0.007 \\
\hline & Adjusted $\dagger$ & 1.08 (0.63 to 1.84$)$ & 1.09 (0.64 to 1.84$)$ & 0.38 (0.20 to 0.72$)$ & 1.20 (0.64 to 2.24$)$ & 1.05 (0.46 to 2.42$)$ & 1.0 & 0.006 \\
\hline
\end{tabular}

*Likelihood ratio test.

†Adjusted for family income and maternal education at birth, maternal body mass index, skin colour, birth weight, gestational age, maternal smoking during pregnancy, and current behavioural variables (smoking, alcohol drinking, type of diet, and physical exercise).

Table 5 Anthropometry and body composition of 18 year old men according to duration of total breast feeding: adjusted analyses*. Values are means (SEs)

\begin{tabular}{|c|c|c|c|c|c|c|c|}
\hline \multirow[b]{2}{*}{ Outcomes } & \multicolumn{6}{|c|}{ Duration of total breast feeding (months) } & \multirow[b]{2}{*}{$P$ value } \\
\hline & $<1$ & $1-2$ & $3-5$ & $6-8$ & 9-11 & $\geq 12$ & \\
\hline Body mass index & $23.0(0.2)$ & $22.9(0.2)$ & $22.6(0.2)$ & $22.9(0.3)$ & $23.3(0.4)$ & $23.0(0.2)$ & 0.35 \\
\hline Fat mass percentage & $17.5(0.2)$ & $17.7(0.2)$ & $17.6(0.2)$ & $17.8(0.2)$ & $18.2(0.3)$ & $17.8(0.2)$ & 0.24 \\
\hline Fat mass/height ${ }^{2}$ & $4.1(0.1)$ & $4.1(0.1)$ & $4.0(0.1)$ & $4.2(0.1)$ & $4.3(0.1)$ & $4.2(0.1)$ & 0.28 \\
\hline Lean mass/height ${ }^{2}$ & $18.9(0.2)$ & $18.8(0.2)$ & $18.6(0.2)$ & $18.8(0.2)$ & $19.1(0.3)$ & $18.9(0.2)$ & 0.45 \\
\hline Height in $\mathrm{cm}$ & $173.9(0.4)$ & $174.1(0.4)$ & $174.4(0.4)$ & $174.5(0.5)$ & $174.8(0.7)$ & $174.8(0.4)$ & 0.49 \\
\hline Percentage leg/total height & $44.6(0.1)$ & $44.6(0.1)$ & $44.7(0.1)$ & $44.8(0.1)$ & $44.7(0.2)$ & $44.6(0.1)$ & 0.52 \\
\hline
\end{tabular}

*General linear model (general factorial); estimates adjusted for family income and maternal education at birth, maternal body mass index, skin colour, birth weight and gestational age, maternal smoking during pregnancy, and current behavioural variables (smoking, alcohol drinking, type of diet, and physical exercise). The number of participants ranged from 2106 to 2133 , depending on the outcome. 
Table 6 Anthropometry and body composition of 18 year old men according to the duration of predominant breast feeding. Values are means (SDs) unless stated otherwise

\begin{tabular}{|c|c|c|c|c|c|c|c|}
\hline \multirow[b]{2}{*}{ Outcomes } & \multicolumn{5}{|c|}{ Duration of predominant breast feeding (months) } & \multirow[b]{2}{*}{$P$ value* } & \multirow[b]{2}{*}{ All participants } \\
\hline & $<1$ & $1-1.9$ & $2-2.9$ & $3-3.9$ & $\geq 4$ & & \\
\hline Overweight (\%) & 14.9 & 14.0 & 11.4 & 13.1 & 14.5 & 0.63 & 13.5 \\
\hline Obese (\%) & 10.3 & 8.3 & 7.0 & 6.5 & 7.4 & $0.03 \dagger$ & 8.1 \\
\hline Body mass index & $22.5(3.7)$ & $22.2(3.4)$ & $22.2(3.7)$ & $22.5(4.0)$ & $22.4(3.6)$ & 0.70 & $22.3(3.7)$ \\
\hline Fat mass/height ${ }^{2}$ & $4.0(1.2)$ & $4.0(1.1)$ & $4.0(1.1)$ & $4.0(1.1)$ & $4.0(1.1)$ & 0.95 & $4.0(1.1)$ \\
\hline Lean mass/height ${ }^{2}$ & $18.4(2.9)$ & $18.2(2.8)$ & $18.2(2.8)$ & $18.3(2.8)$ & $18.6(2.9)$ & 0.42 & $18.4(2.8)$ \\
\hline Height in $\mathrm{cm}$ & $173.0(6.9)$ & $173.2(6.9)$ & $173.3(6.4)$ & $173.9(6.6)$ & $173.6(7.0)$ & $0.03 \dagger$ & $173.4(6.7)$ \\
\hline Percentage leg/total height & $44.6(1.4)$ & $44.5(1.3)$ & $44.7(1.3)$ & $44.7(1.3)$ & $44.7(1.4)$ & $0.06 \dagger$ & $44.6(1.3)$ \\
\hline No of participants $\ddagger$ & 593 & 312 & 393 & 546 & 237 & - & 2081 \\
\hline
\end{tabular}

${ }^{*}$ Test for heterogeneity $\left(\chi^{2}\right.$ test for proportions; analysis of variance for means).

†Test for linear trend.

†Number of participants ranged from 2051 to 2081 , depending on the outcome.

Table 7 Logistic regression analyses for prevalence of overweight and obesity among 18 year old men according to duration of predominant breast feeding $(n=1993)$

\begin{tabular}{|c|c|c|c|c|c|c|c|}
\hline \multirow[b]{2}{*}{ Outcomes } & \multirow[b]{2}{*}{ Model } & \multicolumn{5}{|c|}{ Odds ratio (95\% $\mathrm{Cl})$ according to duration of predominant breast feeding (months) } & \multirow[b]{2}{*}{ P value ${ }^{\star}$} \\
\hline & & $<1$ & $1-1.9$ & $2-2.9$ & $3-3.9$ & $\geq 4$ & \\
\hline \multirow[t]{2}{*}{ Overweight (\%) } & Crude & 1.03 (0.67 to 1.58$)$ & 0.96 (0.60 to 1.56$)$ & 0.76 (0.47 to 1.23 ) & 0.89 (0.58 to 1.38$)$ & 1.0 & 0.62 \\
\hline & Adjusted $†$ & 1.05 (0.69 to 1.58$)$ & 0.82 (0.51 to 1.32$)$ & 0.86 (0.55 to 1.34$)$ & 0.82 (0.54 to 1.25$)$ & 1.0 & 0.56 \\
\hline \multirow[t]{2}{*}{ Obese (\%) } & Crude & 1.43 (0.82 to 2.49$)$ & $1.12(0.60$ to 2.10$)$ & 0.94 (0.50 to 1.74 ) & 0.87 (0.49 to 1.56$)$ & 1.0 & $0.03 \ddagger$ \\
\hline & Adjusted $\dagger$ & $1.42(0.79$ to 2.56$)$ & $1.14(0.59$ to 2.22$)$ & $1.02(0.53$ to 1.94$)$ & 0.80 (0.43 to 1.48$)$ & 1.0 & $0.03 \ddagger$ \\
\hline
\end{tabular}

*Likelihood ratio test.

†Adjusted for family income and maternal education at birth, maternal body mass index, skin colour, birth weight, gestational age, maternal smoking during pregnancy, and current behavioural variables (smoking, alcohol drinking, type of diet, and physical exercise). †Test for linear trend.

for body mass index of $25 \mathrm{~kg} / \mathrm{m}^{2}$ and $30 \mathrm{~kg} / \mathrm{m}^{2}$; results were virtually unchanged.

\section{Discussion}

\section{Main findings and interpretation}

Our results were mostly negative. Neither the duration of total breast feeding nor that of predominant breast feeding had marked effects on the anthropometric or body composition indices. Allowance for confounding factors eliminated some of the associations observed in the crude analyses. Two significant associations remained after adjustment. The first was a greater than $50 \%$ reduction in obesity in participants breast fed for three to five months. Although it is tempting to relate this finding to the "critical window" theory of development, it has to be interpreted with caution, because we did not find significant reductions in this group for any of the other measures of adiposity, and because we had no a priori hypothesis regarding a protective effect of intermediate duration of breast feeding.

The second significant finding was a linear trend for a reduction in obesity with increasing duration of predominant breast feeding. In addition to breast milk, predominantly breastfed babies received water, herbal teas, or both, usually starting in the first week of life, and most of them received fruit juices from the age of 2-3 months. Exclusive breast feeding was rare in this population, so its effect cannot be assessed. One might speculate whether truly exclusive breast feeding, if present, would have resulted in a clearer pattern of association with obesity. Nevertheless, we found no associations between predominant breast feeding and any of the other measures of adiposity studied. We also observed a possible positive effect of total duration of breast feeding on adult height $(\mathrm{P}=0.06)$, a finding that was not reported in the available literature.

This study has some limitations. About $21 \%$ of the participants were lost to follow up over the 18 year period; losses were higher at both extremes of the socioeconomic scale and were not associated with duration of breast feeding. Another limitation is that results are not available for women. About $4.5 \%$ of the cohort died by 18 years of age, but $69 \%$ of these deaths occurred before 6 months of age. Survivor bias is therefore unlikely to have affected our analyses.

Table 8 Anthropometry and body composition of 18 year old men according to duration of predominant breast feeding: adjusted analyses*. Values are means (SEs)

\begin{tabular}{|c|c|c|c|c|c|c|}
\hline \multirow[b]{2}{*}{ Outcomes } & \multicolumn{5}{|c|}{ Duration of predominant breast feeding (months) } & \multirow[b]{2}{*}{$P$ value } \\
\hline & $<1$ & $1-1.9$ & $2-2.9$ & 3-3.9 & $\geq 4$ & \\
\hline Body mass index & $23.1(0.2)$ & $22.9(0.2)$ & $22.9(0.2)$ & $22.8(0.2)$ & $23.1(0.3)$ & 0.61 \\
\hline Fat mass percentage & $17.7(0.2)$ & $17.6(0.2)$ & $17.8(0.2)$ & $17.8(0.2)$ & $17.5(0.2)$ & 0.68 \\
\hline Fat mass $/$ height $^{2}$ & $4.1(0.1)$ & $4.1(0.1)$ & $4.1(0.1)$ & $4.1(0.1)$ & $4.1(0.1)$ & 0.96 \\
\hline Lean mass/height ${ }^{2}$ & $19.0(0.1)$ & $18.8(0.2)$ & $18.8(0.2)$ & $18.8(0.1)$ & $19.1(0.2)$ & 0.38 \\
\hline Height in $\mathrm{cm}$ & $174.1(0.4)$ & $174.5(0.4)$ & $174.3(0.4)$ & $174.1(0.4)$ & $174.5(0.5)$ & 0.79 \\
\hline Percentage leg/total height & $44.7(0.1)$ & $44.6(0.1)$ & $44.7(0.1)$ & $44.6(0.1)$ & $44.6(0.1)$ & 0.52 \\
\hline
\end{tabular}

*General linear model (general factorial); estimates adjusted for family income and maternal education at birth, maternal body mass index, skin colour, birth weight and gestational age, maternal smoking during pregnancy, and current behavioural variables (smoking, alcohol drinking, type of diet, and physical exercise). The number of participants ranged from 2034 to 2060 , depending on the outcome. 


\section{Comparison with literature}

A review of the English language literature on breast feeding and adolescent adiposity found, in addition to the study by Gillman et al mentioned in the introduction, ${ }^{4}$ three other studies. A Canadian case-control study compared obese, overweight, and non-obese 12-18 year olds. ${ }^{14}$ Feeding history was ascertained retrospectively by telephone. A significant increasing trend in duration of breast feeding occurred among the three groups, but no additional benefit from delayed introduction of solids was seen, in either the crude or the adjusted analyses. Tulldahl et al studied the effect of duration of breast feeding on height, skinfolds, and body composition in 18 year olds..$^{15}$ Those who were breast fed for longer periods tended to be shorter and leaner, but not all associations were significant. In a study of 136 rural American teenagers, breast feeding for two months or less was positively associated with obesity. ${ }^{16}$ This association was only present in the lower socioeconomic status group. However, the association disappeared in the adjusted analysis.

Our study differed from the four studies cited above, as it was a prospective cohort study assessing the association of duration and exclusivity of breast feeding with several measures of adolescent adiposity. The only other cohort study on the subject, the growing up today study, was a partly retrospective cohort in which information on breast feeding was obtained through maternal recall when participants were aged 9-14 years, with an overall response rate of less than $50 \%{ }^{4}$

\section{Conclusions}

We cannot at this stage make a strong statement about the protective role of breast feeding against obesity in adolescence. Although the subject of breast feeding and obesity in childhood is also still controversial, ${ }^{1}$ at least one study suggests that there is an inverse dose-response relation between the duration of breast feeding and obesity at 5 - 6 years of age.$^{17}$ Our results do not support this finding.

Regardless of the role breast feeding may have in preventing obesity, it has been consistently associated with many advantages for the mother and child, ranging from decreased childhood mortality to a likely protection against breast cancer. $^{18}{ }^{19}$ The continued protection, promotion, and support of breast feeding remains a major public health priority.

We acknowledge the logistical support of the Brazilian Army, in particular Colonel J C Poppe, Major L M Coutinho, Captain J L Barros, and Mr O Petiz.

Contributors: CGV and FCB have coordinated the cohort study from its inception, supervising data collection and analyses and writing up the manuscript. RCL coordinated the fieldwork for the current phase of the study and constructed the database. BLH carried out data analyses and contributed to the writing of the manuscript. JW advised on body composition measurement, carried out the validation study for body composition, and provided critical inputs to the analysis and writing up of the manuscript. All authors approved the final version of the paper. CGV is the guarantor for the paper.

Funding: The study was financed by the Division of Child and Adolescent Health of the World Health Organization, by the Programa Nacional de Núcleos de Excelência (PRONEX), and

\section{What is already known on this topic}

Although no consensus exists, some recent papers suggest that breast feeding may protect against overweight and obesity in adolescence

\section{What this study adds}

This is the largest birth cohort study reporting on the effect of breast feeding on several measures of adiposity, including body composition, in adolescence

Among 18 year old male Brazilians, duration of neither total nor predominant breast feeding was consistently protective against adolescent adiposity

by the Ministry of Health of Brazil. Earlier phases of the cohort study were financed by the International Development Research Center of Canada and by the Overseas Development Administration of the United Kingdom.

Competing interests: None declared.

Ethical approval: The Brazilian Medical Research Council approved the study protocol.

1 Butte NF. The role of breastfeeding in obesity. Pediatr Clin North Am 2001;48:189-98.

2 Dietz WH. Breastfeeding may help prevent childhood overweight. JAMA 2001;285:2506-7.

3 Hediger ML, Overpeck MD, Kuczmarski RJ, Ruan WJ. Association between infant breastfeeding and overweight in young children. JAMA 2001;285:2453-60.

4 Gillman MW, Rifas-Shiman SL, Camargo CA Jr, Berkey CS, Frazier AL, Rockett HR, et al. Risk of overweight among adolescents who were breastfed as infants. JAMA 2001;285:2461-7.

5 Dewey K. Is breastfeeding protective against child obesity? J Hum Lact 2003;19:9-18.

6 Barros FC, Victora CG, Vaughan JP. The Pelotas birth cohort study, 19821987: strategies for following up 6,000 children in a developing country. Perinat Pediatr Epidemiol 1990;4:267-82.

7 Victora CG, Barros FC, Lima RC, Behague DP, Gonçalves H, Horta BL, et al. The Pelotas (Brazil) birth cohort study, 1982-2001. Cad Saude Publica 2003 (in press).

8 World Health Organization, Division of Diarrhoeal and Acute Respiratory Disease Control. Indicators for assessing breast-feeding practices. Geneva: WHO, 1991

9 Block G, Clifford C, Naughton MD, Henderson M, McAdams M. A brief dietary screen for high fat intake.J Nutr Educ 1989;21:199-207.

10 World Health Organization, Expert Committee on Nutrition. Physical status: uses and interpretation of anthropometry. Geneva: WHO, 1995. (WHO Technical Report Series, No 854.)

11 Wells JCK, Gigante DP, Wright A, Hallal PC, Victora CG. Validation of leg-to-leg impedance for body composition assessment among Brazilian males aged 16-19 years. Int J Body Composition Res 2003;1(2):1-6.

12 VanItallie TB, Yang M, Heymsfield SB, Funk RC, Boileau RA. Height-normalized indices of the body fat-free mass and fat mass: potentially useful indicators of nutritional status. Am J Clin Nutr 1990;52:953-9.

13 Huttly SRA, Victora CG, Barros FC, Beria JU, Vaughan JP. Do mothers overestimate breastfeeding duration? An example of recall bias from a study in Southern Brazil. Am J Epidemiol 1990;132:572-5.

14 Kramer MS. Do breast-feeding and delayed introduction of solid foods protect against subsequent obesity? J Pediatr 1981;98:883-7.

15 Tulldahl J, Pettersson K, Andersson SW, Hulthen L. Mode of infant feeding and achieved growth in adolescence: early feeding patterns in relation to growth and body composition in adolescence. Obes Res 1999;7:431-7.

16 Elliott KG, Kjolhede CL, Gournis E, Rasmussen KM. Duration of breastfeeding associated with obesity during adolescence. Obes Res 1997:5:538-

17 Von Kries R, Koletzko B, Sauerwald T, von Mutius E. Does breast-feeding protect against childhood obesity? Adv Exp Med Biol 2000;478:29-39.

18 WHO Collaborative Study Team on the Role of Breastfeeding on the Prevention of Infant Mortality. How much does breastfeeding protect against infant and child mortality due to infectious diseases? A pooled analysis of six studies from less developed countries. Lancet 2000;355:451-5.

19 Beral V, Bull D, Doll R, Peto R, Reeves G. Breast cancer and breastfeeding. Lancet 2003;361:e177.

(Accepted 24 July 2003) 